\title{
A new perspective of vasculogenic mimicry: EMT and cancer stem cells (Review)
}

\author{
YUN-LONG FAN $^{1 *}$, MIN ZHENG $^{1 *}$, YA-LING TANG ${ }^{1,2}$ and XIN-HUA LIANG ${ }^{1,3^{*}}$ \\ ${ }^{1}$ State Key Laboratory of Oral Diseases; Departments of ${ }^{2}$ Oral Pathology, and ${ }^{3}$ Oral and Maxillofacial Surgery, \\ West China Hospital of Stomatology, Sichuan University, Chengdu, Sichuan 610041, P.R. China
}

Received January 28, 2013; Accepted July 17, 2013

DOI: $10.3892 / 01.2013 .1555$

\begin{abstract}
Vasculogenic mimicry (VM), a new pattern of tumor microcirculation, is important for the growth and progression of tumors. Epithelial-mesenchymal transition (EMT) is pivotal in malignant tumor progression and VM formation. With increasing knowledge of cancer stem cell (CSC) phenotypes and functions, increasing evidence suggests that CSCs are involved in VM formation. Recent studies have indicated that EMT is relevant to the acquisition and maintenance of stem cell-like characteristics. Thus, in this review we discuss the correlation between CSCs, EMT and VM formation.
\end{abstract}

\section{Contents}

1. Introduction

2. Cancer stem cell (CSC) involvement in vasculogenic mimicry (VM) formation

3. Epithelial-mesenchymal transition (EMT) involvement in VM

4. CSCs are implicated in VM formation by the induction of EMT

5. Perspectives on cancer treatment

\section{Introduction}

For many years, angiogenesis via the sprouting of new vessels from existing ones was considered to be the exclusive method of tumor vascularization (1), and anti-angiogenesis therapies were applied as a promising method to 'starve' tumors.

Correspondence to: Professor Xin-Hua Liang, Department of Oral and Maxillofacial Surgery, West China Hospital of Stomatology, Sichuan University, No. 14, Sec. 3, Renminnan Road, Chengdu, Sichuan 610041, P.R. China

E-mail: tangyaling@scu.edu.cn

*Contributed equally

Key words: cancer stem cell, vasculogenic mimicry, epithelial-mesenchymal transition, angiogenesis, metastasis
However, with the administration of angiogenesis inhibitors primarily targeting endothelial cells, it was identified that the effect of these types of drugs was limited. This indicated that there may be other supplementary blood supply patterns used to nourish tumors. In 1999, Maniotis et al (2) first reported that highly aggressive and metastatic melanoma cells are able to form highly patterned vascular channels lined externally by tumor cells, without the existence of endothelial cells. This process was termed vasculogenic mimicry (VM), which is independent of angiogenesis, and is composed of tumor cells and a basement membrane. VM was categorized into two distinctive types: the patterned matrix type (2) and the tubular type (3). Blood plasma and red blood cells are able to flow in the nonendothelial cell-lined vessel-like structures $(2,4)$, and a VM-angiogenesis junction in the central area of the inflammatory breast cancer (IBC) xenografts has been observed (5). This evidence suggests that VM in the tumor mass is connected with host vessels for blood supply and is part of the functional microcirculation.

Subsequently, VM has been observed in numerous types of aggressive tumors, such as colorectal cancer (6), head and neck squamous cell carcinoma (HNSCC) (7-9), glioblastoma $(3,10)$, breast cancer $(11,12)$, ovarian carcinoma $(13,14)$, astrocytoma (15) and Ewing sarcoma (4). Increasing evidence has suggested that patients with tumors undergoing VM have a worse prognosis and VM may be used as an independent predictor of prognosis (16-18). Lin et al (9) analyzed the clinical and pathological significance of VM in 168 cases of laryngeal squamous cell carcinoma (LSCC) and found that VM occurred in LSCC, and LSCC with VM had increased potential for invasion and metastasis. Upile et al (8) showed that HN2b metastatic HNSCC cells lines have higher VM formation properties when compared with the HN2a primary tumor cell line, and endothelial growth factor antibodies discouraged VM formation.

Additionally, certain studies demonstrated that administration of angiogenesis inhibitors did not suppress the formation of VM, and even induced extracellular matrix-rich tubular network formation in vitro (19). Conceivably, VM may play a pivotal role as an alternative pathway for blood supply when the pattern of angiogenesis is inhibited.

Epithelial-mesenchymal transition (EMT) is a reversible dedifferentiation process that converts epithelial cancer cells into dedifferentiated cells with additional mesenchymal 
features. This process is characterized by the loss of epithelial traits and the acquisition of mesenchymal phenotypes (20-23). Activation of EMT triggers tumor cell invasion and metastasis to distant organs. Recently, EMT has been reported to contribute to the formation of VM, and the upregulation of EMT-associated transcription factors has been demonstrated in VM-forming tumor cells $(24,25)$.

Normal tissues and tumors contain a small subset of cells, known as stem cells, with the capacity for self-renewal and the multipotency to differentiate into diverse committed lineages $(26,27)$. Tumors are composed of diverse types of cells (28) and cancer stem cells (CSCs) are at the top of the hierarchical pyramid (26,29-31). Mounting evidence demonstrates that CSCs have the capacity for differentiation along tumor and endothelial lineages $(32,33)$, as well as vascular smooth muscle-like cells (3). VM-engaging tumor cells show a significant expression of both endothelial and tumor phenotypes $(14,34)$, and thus VM may represent the incomplete progress of CSC differentiation into endothelial lineages. Additionally, it has been observed that epithelial cancer cells may be endowed with the self-renewal stem cell phenotype via EMT $(35,36)$. Therefore, in this review, we discuss the correlation between CSCs, EMT and VM formation.

\section{Cancer stem cell (CSC) involvement in vasculogenic mimicry (VM) formation}

CSCs, as defined by the American Association of Cancer Research, are a small subset of cells with the capability of self-renewal and differentiation into the heterogeneous lineages that constitute the tumor mass (26). In reality, this is only a functional definition. Due to the lack of specific markers, the so-called 'CSCs' obtained in almost all experiments are actually a mixture of real CSCs and progenitor cells. In that sense, it is also reasonable to call these cells tumor stem-like cells. Although there is controversy regarding the accurate definition of CSCs, increasing evidence supports the existence of CSCs and the validity of the CSC hypothesis (37). CSCs were first demonstrated in human acute myeloid leukemia (AML) when investigators found that the ability to initiate tumors by transplantation of AML cells into NOD/SCID mice was limited to a $\mathrm{CD} 34^{+} / \mathrm{CD} 38^{-}$subpopulation of leukemic cells (38). CSCs have been further observed in several solid tumors, such as breast $(28)$, brain $(39,40)$, melanoma $(41,42)$, prostate $(43)$, ovarian $(44,45)$ and pancreatic cancers $(46)$, as well as HNSCC (47-53). In addition to the capability of tumor initiation, CSCs have also been implicated in tumor invasion and metastasis. In breast cancer, the CSCs sorted by a number of markers have a higher capability of invasion and metastasis. Balic et al (54) found that the majority of early disseminated cancer cells in bone marrow have a breast CSC phenotype (CD $\left.44^{+} / \mathrm{CD} 24^{-}\right)$. From a retrospective study of 109 patients with IBC, the patient prognosis and metastasis trends showed a significant correlation with aldehyde dehydrogenase 1 (ALDH1) expression, a specific marker of CSCs. Both in vitro and xenograft assays showed that invasion and metastasis in IBC are mediated by a cellular component that exhibits ALDH activity (55). In HNSCC cell lines, based on an invasive assay in vitro and injection of tumor cells into the tail vein of mice, Davis et al (56) found that $\mathrm{CD} 44^{+}$cells have an increased ability to invade through the basement membrane and to form lung metastases. In the peripheral blood of patients with HNSCC, a greater number of $\mathrm{CD} 44^{+}$tumor cells were also observed compared with that of the healthy control group (57). Song et al (58) demonstrated that side population (SP) cells in HNSCC were highly invasive, and the highly metastatic M3a2 and M4e HNSCC cell lines contained a greater number of SP cells in comparison with the 686LN parental HNSCC cell line that has low metastatic potential. It was deduced that SP cells may be a major driving force in head and neck tumor formation and metastasis. Goldie et al (59) reported that upregulation of FRMD4A, a human epidermal stem cell marker, occurs in primary human HNSCCs, where high expression levels correlate with increased risk of relapse. Additionally, FRMD4A silencing was shown to decrease the growth and metastasis of human squamous cell carcinoma xenografts in the skin and tongue.

Furthermore,Hermannetal(46) found thatCD133 ${ }^{+} / \mathrm{CXCR} 4^{+}$ CSCs of pancreatic tumors are crucial in tumor metastasis and $\mathrm{CD}_{133}$ /CXCR4- CSCs are associated with tumorigenesis. On the basis of this finding, CSCs are divided into two categories: Stationary CSCs, which are involved in tumorigenesis, and invasive CSCs, which are associated with the behaviors of invasion and metastasis. Moreover, resistance to conventional treatment has been considered as a problem in cancer therapy. At present, the exact mechanism of resistance is yet to be completely understood. Considering the slow proliferation rate (60), the higher resistance to the hypoxic environment (61) and cell death (62), and the role of the ABC family (such as $\mathrm{ABCB} 1, \mathrm{ABCG} 2$ and $\mathrm{ABCB} 5)$ in pumping drugs out of the cell (63), CSCs are analogous to a reservoir of cells that survive the initial treatment and are responsible for tumor recurrence.

With increasing knowledge of CSC phenotypes and functions, the evidence suggests that CSCs are involved in VM formation. In human breast cancer, by injecting human breast CSCs into SCID mice, Bussolati et al (64) found that a number of the intratumor vessels were of human origin, indicating the involvement of breast CSCs in vessel formation. In melanoma, there is evidence showing that the VM-forming tumor cells express phenotypes that are usually expressed in other cell types, such as endothelial or epithelial cells (11). This indicated that these cells may revert to an undifferentiated, stem-like phenotype (65). Recently, in glioblastoma, Ricci-Vitiani et al (32) and Wang et al (33) found that CD133 ${ }^{+}$glioblastoma stem-like cells are pluripotent and capable of differentiation along tumor and endothelial lineages $(33,66)$, as well as mixed endothelial cell lineages, with co-expression of the tumor phenotype (32). On the analysis of tumor xenografts obtained by orthotopic and subcutaneous injection of human glioblastoma in immunocompromised mice, the authors observed that the vessels in the transplanted tumor were primarily composed of tumor cells with an aberrant endothelial phenotype. The findings indicate that these cells are derived from CSCs, and thus VM may represent an incomplete differentiation of cancer stem-like cells towards the endothelial lineage (Fig. 1). It has been reported that $\mathrm{CD}_{133^{+}}$and $\mathrm{ABCB} 5^{+}$subpopulations are colocalized in melanomas in perivascular niches that

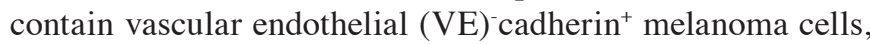
which have the ability to form VM (67). Frank et al (68) found that vascular endothelial growth factor 1 (VEGF-1) signaling 


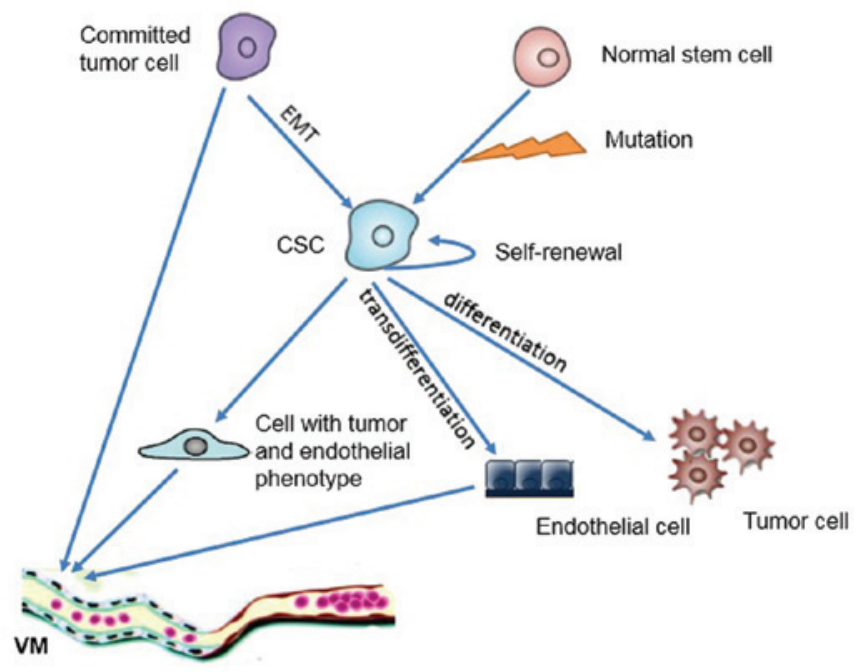

Figure 1. Schematic diagram representing the VM formation involved in CSCs and EMT. VM, vasculogenic mimicry; CSC, cancer stem cell; EMT, epithelial-mesenchymal transition.

plays an important role in this process and knockdown of VEGF receptor 1 blocked the development of $\mathrm{ABCB}^{+} \mathrm{VM}$ morphology. In oral squamous cell carcinoma, Dang and Ramos (69) observed that TRA-1-60 $/ \beta 6^{+}$tumor cells with CSC attributes are able to form vascular-like structures in vivo. However, based on the observation of the melanoma xenograft model, Zhang et al (70) found that VM was the dominant blood supply pattern in the early stage of tumor growth. During tumor growth progression, the level of VM decreased and the number of endothelial-dependent vessels increased. The authors proposed a three-stage blood supply pattern consisting of VM, mosaic vessels and endothelium-dependent vessels. This inverse change tendency between VM and endothelium-dependent vessels may be due to the persistent differentiation of CSCs to endothelial cells without tumor cell phenotypes.

\section{Epithelial-mesenchymal transition (EMT) involvement in VM}

EMT is a crucial process in cancer progression, providing cancer cells with the ability to escape from the primary site, invade stromal tissues and migrate to distant regions of the body. Epithelial cells undergoing EMT are characterized by downregulation of epithelial makers (such as cytokeratin), loss of cell polarity and intercellular adhesion molecules (for instance E-cadherin and occludin), which is concomitant with upregulation of mesenchymal markers (vimentin, $\mathrm{N}$-cadherin and fibronectin) and acquisition of fibroblast-like morphology with cytoskeleton reorganization $(20,22,71)$. The loss of $\mathrm{E}$-cadherin and the gain of $\mathrm{N}$-cadherin expression are known as cadherin switching, a major hallmark of EMT. Cadherin switching was observed in 30 out of 80 HNSCC cases and was closely correlated with histological differentiation, pattern of invasion and lymph node metastasis in HNSCC cases (72). According to analysis of HNSCC specimens and cell lines, Mandal et al (73) demonstrated a close correlation between EMT and aggressive tumor features, including penetrating invasive fronts, high-grade sarcomatoid transformation and lymph node metastasis. A variety of transcription factors such as Snail (Snail1) (74-76), Slug (Snail2) (77), Twist (78), SOX4 (79) and ZEB (80), and several signaling pathways, involving TGF- $\beta$, Wnt, Notch and Hedgehog, have been reported to play significant roles in the process of EMT (81-83). Snail and Slug repress E-cadherin transcription to degrade cell-to-cell adhesion by binding the E-box in the E-cadherin promoter, and inducing tumor cell migration $(74,79,84)$. The transcription factor Twist, a master regulator of embryonic morphogenesis, contributes to metastasis of mammary carcinoma by promoting an EMT (78). Twist1 induced invasion and metastasis of hepatocellular carcinoma (HCC) via downregulation of E-cadherin and increased activity of matrix metalloproteinase (MMP), specifically MMP2 and MMP9 (85). In a spontaneous skin squamous cell carcinoma mouse model, Tsai et al (86) demonstrated that activation of Twist1 is sufficient to promote carcinoma cells to undergo EMT and disseminate into blood circulation. Aigner et al (87) identified that the transcription factor ZEB1 is able to induce the repression of certain polarity genes (Crumbs3, PATJ and HUGL2) to improve tumor cell invasion. Moreover, by virtue of repression of the miR-200 and miR-34a families, respectively, ZEB1 contributes to metastasis by maintenance of the dedifferentiation status and remodeling of cytoskeletal actin $(88,89)$. Furthermore, there is evidence to suggest that these transcription factors function together, but not independently, in order to induce EMT $(84,90)$.

Recently, evidence has shown that EMT is involved in the process of VM formation. In VM-positive colorectal carcinoma samples, Liu et al (24) found that expression of ZEB1 was upregulated. Downregulation of E-cadherin and upregulation of vimentin in the ZEB1-positive group were detected. Knockdown of ZEB1 resulted in a decrease in VM and the restoration of certain epithelial phenotypes, such as VE-cadherin and Flk-1. In HCC, the inhibition of Twist1 expression by the short hairpin RNA markedly reduced VM formation (25). Furthermore, the Bcl-2/Twist1 complex facilitates the nuclear transport of Twist1 and leads to transcriptional activation of a wide range of genes that may increase the tumor cell plasticity, metastasis and VM formation of hepatocellular carcinoma (91). Lirdprapamongkol et al (92) have reported that the poorly-differentiated HCC cell line, SK-Hep-1, with mesenchymal features (high invasiveness and expressing vimentin, with no E-cadherin) could form VM in vitro, while the well-differentiated cell line HepG2 did not form VM. These findings indicated that EMT is involved in VM formation.

\section{CSCs are implicated in VM formation by the induction of EMT}

Researchers have been engaged in discovering the origin of CSCs for a number of years. It is widely accepted that tumor formation is due to the multistep mutation of genomes. Considering the longer lifespan of stem cells, normal stem cells suffer from the accumulation of mutations over time. Thus, it is hypothesized that CSCs derive from normal stem cells with genetic mutations, and this has been demonstrated by independent investigators $(93,94)$. In addition to this mechanism, 
mounting data suggest that differentiated tumor cells may reacquire stemness (95), particularly via EMT induction (35). The endowment of stem cell traits by EMT provided another source for the origin of CSCs. Biddle et al (96) classified the CSCs into two types, namely, non-EMT CSCs and EMT CSCs, based on EMT progression.

An increasing body of evidence shows that EMT is associated with the acquisition of CSC properties. In 2008, Mani et al (35) reported that the induction of EMT in immortalized human mammary epithelial cells results in the acquisition of mesenchymal traits, as well as the expression of stem cell markers. Stem-like cells isolated either from mouse or human mammary glands or mammary carcinomas express EMT markers $(35,97)$. Morel et al $(36)$ also indicated that cells possessing both stem and tumorigenic characteristics of 'CSCs' may be derived from human mammary epithelial cells following the activation of the Ras-MAPK pathway. The acquisition of these stem cell and tumorigenic characteristics is driven by EMT induction. Santisteban et al (98) found that breast tumor cells undergoing EMT induced by $\mathrm{CD}^{+} \mathrm{T}$ cells acquired certain characteristics of breast CSCs, including potent tumorigenicity, resistance to conventional treatment, and the ability to form spheroids. Fang et al (99) demonstrated that Twist 2 is overexpressed in breast cancer cells. Ectopic overexpression of Twist 2 results in the induction of EMT and increases the number of $\mathrm{CD}^{4} 4^{+} / \mathrm{CD} 24^{-}$cells. Breast cancer cells exposed to TGF- $\beta$ and TNF- $\alpha$ lead to the generation of breast cancer cells with stem-like characteristics by induction of EMT (100). In addition to breast cancer, Ryu et al (101) identified that the gastric CSC marker CD44 was significantly associated with the protein expression of Snail-1, ZEB-1 and E-cadherin. In colorectal cancer, EMT induced by brachyury increased the nanog expression and endowed the colorectal cells with stem cell attributes (102). In HNSCC, EMT conferring to stem cell phenotypes has also been observed. Xia et al (103) found that miR-200a regulates the acquisition of stem-like traits by the induction of EMT in nasopharyngeal carcinoma. Knockdown of miR-200a induced EMT progression and resulted in stem cell attributes, including an increasing proportion of SP, sphere formation capacity, in vivo tumorigenicity in nude mice and stem cell marker expression. Chen et al (104) revealed that HNSCC-ALDH1 ${ }^{+}$cells exhibit a high level of expression of Snail, and knockdown of Snail significantly decreased the expression of ALDH1. These data suggest that epithelial cells within tumors are able to convert into CSCs via EMT (Fig. 1). Moreover, Chen et al (105) demonstrated that upregulation of CD133 increased the phosphorylation of Src coupled with EMT transformation, and CD133/Src signaling is a regulatory switch resulting in EMT and stemness properties in HNSCC. This knowledge provides an improved understanding of the origin of CSCs and is a basis for novel cancer therapeutic strategies targeting EMT and CSCs.

VM allows tumor cells to express the endothelial phenotype and play a similar functional role to endothelial cells in forming blood vessel-like structures. In fact, both epithelial and mesenchymal markers have been observed in tumor cells engaged in VM formation $(14,106,107)$. Therefore, in view of the crucial role of EMT in the acquisition of stemness, it is plausible that CSCs are implicated in VM formation by induction of EMT (Fig. 1). Signal transducers and activators of transcription 3 transcription factor plays a critical role in the development and progression of a variety of tumors, including HNSCC, by regulating cell proliferation, cell cycle progression, apoptosis, angiogenesis, immune evasion and EMT, and through effects in CSCs. Garnier et al (108) found that tissue factor overexpression accompanies features of cellular aggressiveness, such as markers of CSCs (CD133), EMT and expression of the angiogenic and prometastatic phenotype. Recently, Gill et al demonstrated that Snail promotes the induction of Flk1 $1^{+}$endothelial cells in an early subset of differentiating mouse embryonic stem cells, depending on fibroblast growth factor signaling as well as the repression of the miR-200 family (109). Hypoxia is one of the fundamental changes in the development and aggressiveness of a variety of solid tumors. It has been recognized to play critical roles in tumor invasion, metastasis, angiogenesis and chemo-radiation resistance. In addition to tumor angiogenesis, HIF-1a is closely associated with VM formation (4,110-112). Recently, Misra et al (113) found that hypoxia-exposure resulted in an upregulation of c-Myc and OCT3/4, and contributed to VM formation. Hypoxia was also recognized as an important regulator of CSCs and EMT through NF- $\mathrm{B}, \mathrm{PI} 3 \mathrm{~K} / \mathrm{Akt} / \mathrm{mTOR}$, Notch, Wnt/ $\beta$-catenin and Hedgehog signaling pathways $(114,115)$. Thus, the hypoxia microenvironment may be important in VM formation through stemness maintenance and EMT induction.

\section{Perspectives on cancer treatment}

It is clear that tumors are able to grow to a size of $\sim 1-2 \mathrm{~mm}^{3}$ depending on the diffusion of oxygen and nutrients (116). In order to break the metabolic restriction and meet the demands of growth, invasion and metastasis, tumors must form their own vessels to provide oxygen and nutrients, and remove metabolic waste. The microcirculation of tumors is heterogeneous, involving sprouting angiogenesis, vasculogenesis, co-opted vessels, mosaic vessels and VM. Angiogenesis was the first mode of vascularization to be discovered and has been extensively investigated. However, the success of anti-angiogenesis treatment remains limited (117). Keunen et al (118) found that anti-VEGF treatment with bevacizumab decreases the number of vessels and blood supply within the GBM xenograft, but it increases the invasion ability. Therefore, it is not sufficient to improve patient survival through anti-angiogenesis therapy alone.

In reality, the coexistence of angiogenesis and VM is common within aggressive tumors. Angiogenesis inhibitors have little or even no effect on VM $(10,19)$ and VM may replace the effect of angiogenesis to provide the tumor with oxygen and nutrients. Moreover, Qu et al (119) reported that anti-angiogenesis therapy may even induce the formation of VM. Clearly, the combination of several treatments targeting angiogenesis and VM is required.

For quite some time, the survival rate of patients with aggressive tumors has remained at a low level, despite the administration of surgery, chemotherapy and radiotherapy. The existence of CSCs was thought to be an underlying cause. Although CSCs comprise only a small proportion of tumor cell populations, CSCs have high resistance to multiple chemotherapeutics and ionizing radiation. Remaining CSCs are able to induce recurrence following treatment with 
chemotherapy and radiotherapy. Furthermore, it has been demonstrated that CSCs are implicated in VM formation. In this context, CSCs have been considered as a promising treatment target in cancer patients with VM. It has been observed that tumors undergoing the process of EMT acquire resistance to chemotherapy (120). EMT is also involved in the acquisition of CSC properties $(35,36,98)$, and EMT-inducing CSCs have been considered as an important origin of CSCs and another target of VM formation in cancer. A combination of targeting EMT and CSCs may be beneficial for anti-VM formation therapy, decreasing invasion and metastasis, and improving the survival rate of patients.

\section{Acknowledgements}

This study was supported by the National Natural Science Foundation of China (grant nos. 81072215, 81172580 and 81272961) and by the Fundamental Research Funds of the Central Universities of China (2011).

\section{References}

1. Hillen F and Griffioen AW: Tumour vascularization: sprouting angiogenesis and beyond. Cancer Metastasis Rev 26: 489-502, 2007.

2. Maniotis AJ, Folberg R, Hess A, et al: Vascular channel formation by human melanoma cells in vivo and in vitro: vasculogenic mimicry. Am J Pathol 155: 739-752, 1999.

3. El Hallani S, Boisselier B, Peglion F, et al: A new alternative mechanism in glioblastoma vascularization: tubular vasculogenic mimicry. Brain 133: 973-982, 2010

4. van der Schaft DW, Hillen F, Pauwels P, et al: Tumor cell plasticity in Ewing sarcoma, an alternative circulatory system stimulated by hypoxia. Cancer Res 65: 11520-11528, 2005.

5. Shirakawa K, Kobayashi H, Heike Y, et al: Hemodynamics in vasculogenic mimicry and angiogenesis of inflammatory breast cancer xenograft. Cancer Res 62: 560-566, 2002.

6. Ricci-Vitiani L, Lombardi DG, Pilozzi E, et al: Identification and expansion of human colon-cancer-initiating cells. Nature 445: 111-115, 2007.

7. Wang W, Lin P, Han C, Cai W, Zhao X and Sun B: Vasculogenic mimicry contributes to lymph node metastasis of laryngeal squamous cell carcinoma. J Exp Clin Cancer Res 29: 60, 2010.

8. Upile T, Jerjes W, Radhi H, et al: Vascular mimicry in cultured head and neck tumour cell lines. Head Neck Oncol 3: 55, 2011.

9. Lin P, Wang W, Sun BC, et al: Vasculogenic mimicry is a key prognostic factor for laryngeal squamous cell carcinoma: a new pattern of blood supply. Chin Med J (Engl) 125: 3445-3449, 2012

10. Francescone R, Scully S, Bentley B, et al: Glioblastoma-derived tumor cells induce vasculogenic mimicry through Flk-1 protein activation. J Biol Chem 287: 24821-24831, 2012.

11. Shirakawa K, Wakasugi H, Heike Y, et al: Vasculogenic mimicry and pseudo-comedo formation in breast cancer. Int J Cancer 99 821-828, 2002.

12. Ponti D, Costa A, Zaffaroni N, et al: Isolation and in vitro propagation of tumorigenic breast cancer cells with stem/progenitor cell properties. Cancer Res 65: 5506-5511, 2005.

13. Tang HS, Feng YJ and Yao LQ: Angiogenesis, vasculogenesis, and vasculogenic mimicry in ovarian cancer. Int $J$ Gynecol Cancer 19: 605-610, 2009.

14. Su M, Feng YJ, Yao LQ, et al: Plasticity of ovarian cancer cell SKOV3ip and vasculogenic mimicry in vivo. Int J Gynecol Cancer 18: 476-486, 2008.

15. Liu Z, Li Y, Zhao W, Ma Y and Yang X: Demonstration of vasculogenic mimicry in astrocytomas and effects of Endostar on U251 cells. Pathol Res Pract 207: 645-651, 2011.

16. Baeten CI, Hillen F, Pauwels P, de Bruine AP and Baeten CG: Prognostic role of vasculogenic mimicry in colorectal cancer. Dis Colon Rectum 52: 2028-2035, 2009.

17. Warso MA, Maniotis AJ, Chen X, et al: Prognostic significance of periodic acid-Schiff-positive patterns in primary cutaneous melanoma. Clin Cancer Res 7: 473-477, 2001.
18. Folberg R, Rummelt V, Parys-Van Ginderdeuren R, et al: The prognostic value of tumor blood vessel morphology in primary uveal melanoma. Ophthalmology 100: 1389-1398, 1993.

19. van der Schaft DW, Seftor RE, Seftor EA, et al: Effects of angiogenesis inhibitors on vascular network formation by human endothelial and melanoma cells. J Natl Cancer Inst 96: 1473-1477, 2004.

20. Kalluri R and Neilson EG: Epithelial-mesenchymal transition and its implications for fibrosis. J Clin Invest 112: 1776-1784, 2003.

21. Eccles SA and Welch DR: Metastasis: recent discoveries and novel treatment strategies. Lancet 369: 1742-1757, 2007.

22. Thiery JP, Acloque H, Huang RY and Nieto MA: Epithelial-mesenchymal transitions in development and disease. Cell 139: 871-890, 2009.

23. Thiery JP: Epithelial-mesenchymal transitions in tumour progression. Nat Rev Cancer 2: 442-454, 2002.

24. Liu Z, Sun B, Qi L, Li H, Gao J and Leng X: Zinc finger E-box binding homeobox 1 promotes vasculogenic mimicry in colorectal cancer through induction of epithelial-to-mesenchymal transition. Cancer Sci 103: 813-820, 2012.

25. Sun T, Zhao N, Zhao XL, et al: Expression and functional significance of Twist1 in hepatocellular carcinoma: its role in vasculogenic mimicry. Hepatology 51: 545-556, 2010.

26. Clarke MF, Dick JE, Dirks PB, et al: Cancer stem cells perspectives on current status and future directions: AACR Workshop on cancer stem cells. Cancer Res 66: 9339-9344, 2006.

27. Shipitsin M and Polyak K: The cancer stem cell hypothesis: in search of definitions, markers, and relevance. Lab Invest 88: 459-463, 2008.

28. Al-Hajj M, Wicha MS, Benito-Hernandez A, Morrison SJ and Clarke MF: Prospective identification of tumorigenic breast cancer cells. Proc Natl Acad Sci USA 100: 3983-3988, 2003.

29. O'Brien CA, Pollett A, Gallinger S and Dick JE: A human colon cancer cell capable of initiating tumour growth in immunodeficient mice. Nature 445: 106-110, 2007.

30. Rosen JM and Jordan CT: The increasing complexity of the cancer stem cell paradigm. Science 324: 1670-1673, 2009.

31. Singh SK, Hawkins C, Clarke ID, et al: Identification of human brain tumour initiating cells. Nature 432: 396-401, 2004.

32. Ricci-Vitiani L, Pallini R, Biffoni M, et al: Tumour vascularization via endothelial differentiation of glioblastoma stem-like cells. Nature 468: 824-828, 2010.

33. Wang R, Chadalavada K, Wilshire J, et al: Glioblastoma stem-like cells give rise to tumour endothelium. Nature 468: 829-833, 2010.

34. Dong J, Zhao Y, Huang Q, et al: Glioma stem/progenitor cells contribute to neovascularization via transdifferentiation. Stem Cell Rev 7: 141-152, 2011.

35. Mani SA, Guo W, Liao MJ, et al: The epithelial-mesenchymal transition generates cells with properties of stem cells. Cell 133: 704-715, 2008.

36. Morel AP, Lièvre M, Thomas C, Hinkal G, Ansieau S and Puisieux A: Generation of breast cancer stem cells through epithelial-mesenchymal transition. PLoS One 3: e2888, 2008.

37. Chen J, Li Y, Yu TS, et al: A restricted cell population propagates glioblastoma growth after chemotherapy. Nature 488: 522-526, 2012.

38. Lapidot T, Sirard C, Vormoor J, et al: A cell initiating human acute myeloid leukaemia after transplantation into SCID mice. Nature 367: 645-648, 1994.

39. Hemmati HD, Nakano I, Lazareff JA, et al: Cancerous stem cells can arise from pediatric brain tumors. Proc Natl Acad Sci USA 100: 15178-15183, 2003

40. Singh SK, Clarke ID, Terasaki M, et al: Identification of a cancer stem cell in human brain tumors. Cancer Res 63: 5821-5828, 2003.

41. Fang D, Nguyen TK, Leishear K, et al: A tumorigenic subpopulation with stem cell properties in melanomas. Cancer Res 65: 9328-9337, 2005

42. Schatton T, Murphy GF, Frank NY, et al: Identification of cells initiating human melanomas. Nature 451: 345-349, 2008.

43. Collins AT, Berry PA, Hyde C, Stower MJ and Maitland NJ: Prospective identification of tumorigenic prostate cancer stem cells. Cancer Res 65: 10946-10951, 2005.

44. Bapat SA, Mali AM, Koppikar CB and Kurrey NK: Stem and progenitor-like cells contribute to the aggressive behavior of human epithelial ovarian cancer. Cancer Res 65: 3025-3029, 2005.

45. Alvero AB, Chen $\mathrm{R}, \mathrm{Fu} \mathrm{HH}$, et al: Molecular phenotyping of human ovarian cancer stem cells unravel the mechanisms for repair and chemo-resistance. Cell Cycle 8: 158-166, 2009. 
46. Hermann P, Huber S, Herrler T, et al: Distinct populations of cancer stem cells determine tumor growth and metastatic activity in human pancreatic cancer. Cell Stem Cell 1: 313-323, 2007.

47. Sun S and Wang Z: Head neck squamous cell carcinoma c-Met(+) cells display cancer stem cell properties and are responsible for cisplatin-resistance and metastasis. Int J Cancer 129: 2337-2348, 2011.

48. Monroe MM, Anderson EC, Clayburgh DR and Wong MH: Cancer stem cells in head and neck squamous cell carcinoma. J Oncol 2011: 762780, 2011.

49. Sayed SI, Dwivedi RC, Katna R, et al: Implications of understanding cancer stem cell (CSC) biology in head and neck squamous cell cancer. Oral Oncol 47: 237-243, 2011.

50. Zito G, Richiusa P, Bommarito A, et al: In vitro identification and characterization of CD133(pos) cancer stem-like cells in anaplastic thyroid carcinoma cell lines. PLoS One 3: e3544, 2008 .

51. Wang J, Guo LP, Chen LZ, Zeng YX and Lu SH: Identification of cancer stem cell-like side population cells in human nasopharyngeal carcinoma cell line. Cancer Res 67: 3716-3724, 2007.

52. Prince ME, Sivanandan R, Kaczorowski A, et al: Identification of a subpopulation of cells with cancer stem cell properties in head and neck squamous cell carcinoma. Proc Natl Acad Sci USA 104: 973-978, 2007.

53. Prince ME and Ailles LE: Cancer stem cells in head and neck squamous cell cancer. J Clin Oncol 26: 2871-2875, 2008.

54. Balic M, Lin H, Young L, et al: Most early disseminated cancer cells detected in bone marrow of breast cancer patients have a putative breast cancer stem cell phenotype. Clin Cancer Res 12: 5615-5621, 2006

55. Charafe-Jauffret E, Ginestier C, Iovino F, et al: Aldehyde dehydrogenase 1-positive cancer stem cells mediate metastasis and poor clinical outcome in inflammatory breast cancer. Clin Cancer Res 16: 45-55, 2010.

56. Davis SJ, Divi V, Owen JH, et al: Metastatic potential of cancer stem cells in head and neck squamous cell carcinoma. Arch Otolaryngol Head Neck Surg 136: 1260-1266, 2010.

57. Faber A, Barth C, Hörmann K, et al: CD44 as a stem cell marker in head and neck squamous cell carcinoma. Oncol Rep 26 321-326, 2011.

58. Song J, Chang I, Chen Z, Kang M and Wang CY: Characterization of side populations in HNSCC: highly invasive, chemoresistant and abnormal Wnt signaling. PLoS One 5: e11456, 2010.

59. Goldie SJ, Mulder KW, Tan DW, Lyons SK, Sims AH and Watt FM: FRMD4A upregulation in human squamous cell carcinoma promotes tumor growth and metastasis and is associated with poor prognosis. Cancer Res 72: 3424-3436, 2012.

60. La Fleur L, Johansson AC and Roberg K: A CD44high/EGFRlow subpopulation within head and neck cancer cell lines shows an epithelial-mesenchymal transition phenotype and resistance to treatment. PLoS One 7: e44071, 2012

61. Tamara Marie-Egyptienne DT, Lohse I and Hill RP: Cancer stem cells, the epithelial to mesenchymal transition (EMT) and radioresistance: potential role of hypoxia. Cancer Lett: Nov 28 , 2012 (Epub ahead of print). doi: 10.1016/j.canlet.2012.11.019.

62. Todaro M, Alea MP, Di Stefano AB, et al: Colon cancer stem cells dictate tumor growth and resist cell death by production of interleukin-4. Cell Stem Cell 1: 389-402, 2007.

63. Cheung ST, Cheung PF, Cheng CK, Wong NC and Fan ST: Granulin-epithelin precursor and ATP-dependent binding cassette (ABC)B5 regulate liver cancer cell chemoresistance. Gastroenterology 140: 344-355, 2011.

64. Bussolati B, Grange C, Sapino A and Camussi G: Endothelial cell differentiation of human breast tumour stem/progenitor cells. J Cell Mol Med 13: 309-319, 2009.

65. Hendrix MJ, Seftor EA, Meltzer PS, et al: Expression and functional significance of VE-cadherin in aggressive human melanoma cells: role in vasculogenic mimicry. Proc Natl Acad Sci USA 98: 8018-8023, 2001.

66. Soda Y, Marumoto T, Friedmann-Morvinski D, et al: Transdifferentiation of glioblastoma cells into vascular endothelial cells. Proc Natl Acad Sci USA 108: 4274-4280, 2011.

67. Lai CY, Schwartz BE and Hsu MY: CD133+ melanoma subpopulations contribute to perivascular niche morphogenesis and tumorigenicity through vasculogenic mimicry. Cancer Res 72: 5111-5118, 2012.

68. Frank NY, Schatton T, Kim S, et al: VEGFR-1 expressed by malignant melanoma-initiating cells is required for tumor growth. Cancer Res 71: 1474-1485, 2011.
69. Dang D and Ramos DM: Identification of $\alpha v \beta 6$-positive stem cells in oral squamous cell carcinoma. Anticancer Res 29: 2043-2049, 2009.

70. Zhang S, Guo H, Zhang D, et al: Microcirculation patterns in different stages of melanoma growth. Oncol Rep 15: 15-20, 2006

71. Polyak K and Weinberg RA: Transitions between epithelial and mesenchymal states: acquisition of malignant and stem cell traits. Nat Rev Cancer 9: 265-273, 2009.

72. Nguyen PT, Kudo Y, Yoshida M, Kamata N, Ogawa I and Takata T: $\mathrm{N}$-cadherin expression is involved in malignant behavior of head and neck cancer in relation to epithelial-mesenchymal transition. Histol Histopathol 26: 147-156, 2011.

73. Mandal M, Myers JN, Lippman SM, et al: Epithelial to mesenchymal transition in head and neck squamous carcinoma: association of Src activation with E-cadherin down-regulation, vimentin expression, and aggressive tumor features. Cancer 112: 2088-2100, 2008.

74. Batlle E, Sancho E, Franci C, et al: The transcription factor snail is a repressor of E-cadherin gene expression in epithelial tumour cells. Nat Cell Biol 2: 84-89, 2000.

75. Cano A, Pérez-Moreno MA, Rodrigo I, et al: The transcription factor snail controls epithelial-mesenchymal transitions by repressing E-cadherin expression. Nat Cell Biol 2: 76-83, 2000.

76. Zhang A, Chen G, Meng L, et al: Antisense-Snail transfer inhibits tumor metastasis by inducing E-cadherin expression. Anticancer Res 28: 621-628, 2008.

77. Hajra KM, Chen DY and Fearon ER: The SLUG zinc-finger protein represses E-cadherin in breast cancer. Cancer Res 62: 1613-1618, 2002

78. Yang J, Mani SA, Donaher JL, et al: Twist, a master regulator of morphogenesis, plays an essential role in tumor metastasis. Cell 117: 927-939, 2004

79. Zhang J, Liang Q, Lei Y, et al: SOX4 induces epithelial-mesenchymal transition and contributes to breast cancer progression. Cancer Res 72: 4597-4608, 2012.

80. Eger A, Aigner K, Sonderegger S, et al: DeltaEF1 is a transcriptional repressor of E-cadherin and regulates epithelial plasticity in breast cancer cells. Oncogene 24: 2375-2385, 2005.

81. Huber MA, Kraut N and Beug H: Molecular requirements for epithelial-mesenchymal transition during tumor progression. Curr Opin Cell Biol 17: 548-558, 2005.

82. Porsch H, Bernert B, Mehic M, Theocharis AD, Heldin CH and Heldin P: Efficient TGFbeta-induced epithelial-mesenchymal transition depends on hyaluronan synthase HAS2. Oncogene: Oct 29, 2012 (Epub ahead of print). doi: 10.1038/onc.2012.475.

83. Wu ZQ, Li XY, Hu CY, Ford M, Kleer CG and Weiss SJ: Canonical Wnt signaling regulates Slug activity and links epithelial-mesenchymal transition with epigenetic Breast Cancer 1, Early Onset (BRCA1) repression. Proc Natl Acad Sci USA 109: 16654-16659, 2012

84. Guaita S, Puig I, Franci C, et al: Snail induction of epithelial to mesenchymal transition in tumor cells is accompanied by MUC1 repression and ZEB1 expression. J Biol Chem 277: 39209-39216, 2002.

85. Zhao XL, Sun T, Che N, et al: Promotion of hepatocellular carcinoma metastasis through matrix metalloproteinase activation by epithelial-mesenchymal transition regulator Twist1. J Cell Mol Med 15: 691-700, 2011

86. Tsai JH, Donaher JL, Murphy DA, Chau S and Yang J: Spatiotemporal regulation of epithelial-mesenchymal transition is essential for squamous cell carcinoma metastasis. Cancer Cell 22: 725-736, 2012.

87. Aigner K, Dampier B, Descovich L, et al: The transcription factor ZEB1 (deltaEF1) promotes tumour cell dedifferentiation by repressing master regulators of epithelial polarity. Oncogene 26: 6979-6988, 2007.

88. Wellner U, Schubert J, Burk UC, et al: The EMT-activator ZEB1 promotes tumorigenicity by repressing stemness-inhibiting microRNAs. Nat Cell Biol 11: 1487-1495, 2009.

89. Ahn YH, Gibbons DL, Chakravarti D, et al: ZEB1 drives prometastatic actin cytoskeletal remodeling by downregulating miR-34a expression. J Clin Invest 122: 3170-3183, 2012.

90. Casas E, Kim J, Bendesky A, Ohno-Machado L, Wolfe C. and Yang J: Snail2 is an essential mediator of Twist1-induced epithelial mesenchymal transition and metastasis. Cancer Res 71: 245-254, 2011.

91. Sun T, Sun BC, Zhao XL, et al: Promotion of tumor cell metastasis and vasculogenic mimicry by way of transcription coactivation by Bcl-2 and Twist1: a study of hepatocellular carcinoma. Hepatology 54: 1690-1706, 2011. 
92.Lirdprapamongkol K, Chiablaem K, Sila-Asna M, Surarit R, Bunyaratvej A and Svasti J: Exploring stemness gene expression and vasculogenic mimicry capacity in well- and poorly-differentiated hepatocellular carcinoma cell lines. Biochem Biophys Res Commun 422: 429-435, 2012.

93. Passegué E, Jamieson CH, Ailles LE and Weissman IL: Normal and leukemic hematopoiesis: are leukemias a stem cell disorder or a reacquisition of stem cell characteristics? Proc Natl Acad Sci USA 100 (Suppl 1): 11842-11849, 2003.

94.Prindull G: Hypothesis: cell plasticity, linking embryonal stem cells to adult stem cell reservoirs and metastatic cancer cells? Exp Hematol 33: 738-746, 2005.

95. Notta F, Mullighan CG, Wang JC, et al: Evolution of human BCR-ABL1 lymphoblastic leukaemia-initiating cells. Nature 469: 362-367, 2011

96. Biddle A, Liang X, Gammon L, et al: Cancer stem cells in squamous cell carcinoma switch between two distinct phenotypes that are preferentially migratory or proliferative. Cancer Res 71: 5317-5326, 2011.

97. Damonte P, Gregg JP, Borowsky AD, Keister BA and Cardiff RD: EMT tumorigenesis in the mouse mammary gland. Lab Invest 87: 1218-1226, 2007.

98. Santisteban M, Reiman JM, Asiedu MK, et al: Immune-induced epithelial to mesenchymal transition in vivo generates breast cancer stem cells. Cancer Res 69: 2887-2895, 2009.

99. Fang X, Cai Y, Liu J, et al: Twist2 contributes to breast cancer progression by promoting an epithelial-mesenchymal transition and cancer stem-like cell self-renewal. Oncogene 30: 4707-4720, 2011

100. Asiedu MK, Ingle JN, Behrens MD, Radisky DC and Knutson KL: TGFbeta/TNF(alpha)-mediated epithelial-mesenchymal transition generates breast cancer stem cells with a claudin-low phenotype. Cancer Res 71: 4707-4719, 2011.

101. Ryu HS, Park do J, Kim HH, Kim WH and Lee HS: Combination of epithelial-mesenchymal transition and cancer stem cell-like phenotypes has independent prognostic value in gastric cancer. Hum Pathol 43: 520-528, 2012.

102. Sarkar D, Shields B, Davies ML, Muller J and Wakeman JA: BRACHYURY confers cancer stem cell characteristics on colorectal cancer cells. Int J Cancer 130: 328-337, 2012.

103.Xia H, Cheung WK, Sze J, et al: miR-200a regulates epithelial-mesenchymal to stem-like transition via ZEB2 and beta-catenin signaling. J Biol Chem 285: 36995-37004, 2010.

104. Chen YC, Chen YW, Hsu HS, et al: Aldehyde dehydrogenase 1 is a putative marker for cancer stem cells in head and neck squamous cancer. Biochem Biophys Res Commun 385: 307-313, 2009.

105. Chen YS, Wu MJ, Huang CY, et al: CD133/Src axis mediates tumor initiating property and epithelial-mesenchymal transition of head and neck cancer. PLoS One 6: e28053, 2011.

106.Hendrix MJ, Seftor EA, Hess AR and Seftor RE: Vasculogenic mimicry and tumour-cell plasticity: lessons from melanoma Nat Rev Cancer 3: 411-421, 2003.
107. Pisacane AM, Picciotto F and Risio M: CD31 and CD34 expression as immunohistochemical markers of endothelial transdifferentiation in human cutaneous melanoma. Cell Oncol 29: 59-66, 2007.

108. Garnier D, Milsom C, Magnus N, et al: Role of the tissue factor pathway in the biology of tumor initiating cells. Thromb Res 125 (Suppl 2): S44-S50, 2010

109. Gill JG, Langer EM, Lindsley RC, Cai M, Murphy TL and Murphy KM: Snail promotes the cell-autonomous generation of Flk1(+) endothelial cells through the repression of the microRNA-200 family. Stem Cells Dev 21: 167-176, 2012.

110. Sun B, Zhang D, Zhang S, Zhang W, Guo H and Zhao X: Hypoxia influences vasculogenic mimicry channel formation and tumor invasion-related protein expression in melanoma. Cancer Lett 249: 188-197, 2007.

111. Ma JL, Han SX, Zhu Q, et al: Role of Twist in vasculogenic mimicry formation in hypoxic hepatocellular carcinoma cells in vitro. Biochem Biophys Res Commun 408: 686-691, 2011.

112. Comito G, Calvani M, Giannoni E, et al: HIF-1alpha stabilization by mitochondrial ROS promotes Met-dependent invasive growth and vasculogenic mimicry in melanoma cells. Free Radic Biol Med 51: 893-904, 2011.

113. Misra RM, Bajaj MS and Kale VP: Vasculogenic Mimicry of HT1080 Tumour Cells In Vivo: Critical Role of HIF-1alpha-Neuropilin-1 Axis. PLoS One 7: e50153, 2012.

114. Jiang J, Tang YL and Liang XH: EMT: a new vision of hypoxia promoting cancer progression. Cancer Biol Ther 11: 714-723, 2011.

115. Bao B, Azmi AS, Ali S, et al: The biological kinship of hypoxia with CSC and EMT and their relationship with deregulated expression of miRNAs and tumor aggressiveness. Biochim Biophys Acta 1826: 272-296, 2012.

116. Carmeliet P and Jain RK: Angiogenesis in cancer and other diseases. Nature 407: 249-257, 2000.

117. Xu X and Prestwich GD: Inhibition of tumor growth and angiogenesis by a lysophosphatidic acid antagonist in an engineered three-dimensional lung cancer xenograft model. Cancer 116: $1739-1750,2010$.

118. Keunen O, Johansson M, Oudin A, et al: Anti-VEGF treatment reduces blood supply and increases tumor cell invasion in glioblastoma. Proc Natl Acad Sci USA 108: 3749-3754, 2011.

119. Qu B, Guo L, Ma J and Lv Y: Antiangiogenesis therapy might have the unintended effect of promoting tumor metastasis by increasing an alternative circulatory system. Med Hypotheses 74: $360-361,2010$

120. Cao G, Fehrenbach ML, Williams JT, Finklestein JM, Zhu JX and Delisser HM: Angiogenesis in platelet endothelial cell adhesion molecule-1-null mice. Am J Pathol 175: 903-915, 2009. 